\title{
COMMUNITY MEMORIES FOR SUSTAINABLE URBAN LIVING
}

\author{
Ellie D'Hondt and Matthias Stevens \\ BrusSense Team, Department of Computer Science \\ Vrije Universiteit Brussel, Pleinlaan 2, 1050 Brussels, Belgium \\ eldhondt@vub.ac.be,mstevens@vub.ac.be
}

Keywords: Pollution, Citizen science, Sustainability, Participatory sensing, Geo-localisation, Tagging, Mobile phones.

\begin{abstract}
We propose a particular approach by which computer science can aid on the technological side of sustainable development, which at the same time contributes to raising people's awareness of the issues at hand. In particular we develop a so-called community memory for urban environmental measurement surveys, focusing on noise, microclimate and atmospheric pollution. Our goal is to gather data both in a quantitative way, using participatory mobile sensing, and in a qualitative way, by social tagging. In this way we provide a method for environmental monitoring which is complementary to current modelling approaches.
\end{abstract}

\section{INTRODUCTION}

The past decade an overwhelming amount of evidence has accumulated for the fact that the current organisation of our societies is unmanageable with respect to the available natural resources. In order to guarantee our future well-being we fundamentally have to change our lifestyle so that it becomes sustainable, i.e. so that it achieves an ecological balance by avoiding depletion of natural resources. A lot can and must be done from the technological and policy side, and as such sustainability is now a key issue figuring in many a government directive, company slogan and research project. On the other hand we are still a long way off a global transition in everyday lifestyle, as it is only when people become fully aware of their precarious ecological situation that one can expect the needed behaviour change.

A core ecological issue standing in the way of sustainability is that of environmental pollution, in particular in urban environments. Combined with seasonal conditions this can lead to critical situations, with carbon dioxide, ozone and fine particles being the main concerns. Noise pollution is also a major problem in urban environments, affecting humanbehaviour, well-being, productivity and health. Of course there is already environmental monitoring going on, demanded by ambitious European norms such as the European Environmental Noise Directive 2002/49/EC or guideline 1999/30/EG for Particulate Matter concentrations. Cities and governments are already aware of the need for policy or planning changes to satisfy these norms. However, these efforts are hampered by two problems: one is the inadequacy of current pollution measurements, the other the lack of awareness of the average citizen.

The main issue with current assessment techniques for environmental pollution is that they lack spatio-temporal data granularity. This is because they are based on computer simulations which rely on a very limited amount of actual measurement data only. As an example, a medium-sized city such as Brussels has only thirteen measuring points for air quality, which, considering that air quality can change from one side of the street to the other, is totally inadequate. With propagation models - based on general statistics on traffic flows and industrial activity - these local measurements are extrapolated to wider areas to create pollution maps. These maps only show expected global patterns and are often updated only infrequently. ${ }^{1}$ As a result, it is very hard to evaluate the situation in a given neighbourhood, let alone account for local or accidental noise or atmospheric pollution problems such as road works, street protests, etc., which are a real burden for citizens none the less. Because current environmental monitoring techniques are demanding at the levels of expertise, human resources, computation power, as well as the quality of measuring devices, they are expensive and not scalable enough to improve easily on spatio-temporal granularity. As a consequence, there is no convenient way to assess the individual pollution exposure of citizens, and indeed few efforts have

\footnotetext{
${ }^{1}$ For example, EU norms demand noise maps to be updated every five years.
} 
been made for people-centric monitoring of the environment (Stapelfeldt and Jellyman, 2003).

A second important disadvantage of current datagathering methods is the lack of human involvedness. Numerous international reports have expressed the importance of the participation of all citizens, at all levels, to move towards sustainable development (United Nations Environment Programme, 1992; European Parliament and Council, 2002). Indeed, as is the case with many issues affecting urban life, pollution cannot be tackled by policy makers alone, as it requires consideration of the behaviour of all citizens. In reality, however, citizen participation often occurs only at the decision making level, and as such involves only a limited number of citizens. The problem is one of awareness. Pollution surveys are carried out by a select group of people using expensive and difficult-to-handle equipment. As such most citizens have no access to tools to estimate the quality of their personal environment and how it is affected by their behaviour and that of their peers. Moreover, current environmental measurements are totally decoupled from the average citizen's experience of the situation. Indeed physical measurement data only tell one side of the story, and need to be augmented with subjective, qualitative data that trace out the environment as experienced by individuals. ${ }^{2}$ The bottleneck here is that existing techniques based on survey forms or interviews by social scientists, do not yield enough data to be representative on a large-scale. Furthermore because this data is collected separately it is hard to align it with physical measurement data. As a result valuable information such as knowledge of the source of pollution or subjective experience thereof, is entirely absent.

In this paper we propose a particular approach by which computer science can aid on the technological side of sustainable development, which at the same time contributes to raising people's awareness of the issues at hand. In particular we exploit the democratisation of technology facilitated by the Internet of Things to realise an increase in and democratisation of environmental information. The Internet of Things' vision of connectivity of anyone at anytime to anything is largely supported by the widespread use of mobile phones and advances in sensor technology. Our aim is to put these technologies to use to enable digitally improved citizen science - the idea of having volunteers without scientific training perform research-related tasks such as observation, measurement or computation - in the context of environmen-

\footnotetext{
${ }^{2}$ For example in the case of noise the same intensity of sound can give a totally different subjective experience ranging from pleasant to aggravating.
}

tal monitoring. As the technologies we rely on are intrinsically people-centric, we tackle both the problem of limited spatio-temporal data granularity and that of the lack of human involvedness that are typical of current simulation-based techniques.

\section{PROPOSED SOLUTION}

The technological framework we propose for allowing high-granularity person-centric environmental monitoring is that of community memories. A community memory (Steels, 2008) is a common ICT resource that citizens use to monitor their environment, to visualise gathered data and to strategise about alternatives for keeping it sustainable. We gather data both in a quantitative way, using participatory mobile sensing, and in a qualitative way, by social tagging. Participatory sensing (Burke et al., 2006) appropriates everyday mobile devices such as cellular phones to form interactive, participatory sensory networks that enable public and professional users to gather, analyse and share local knowledge. Social tagging (Steels, 2006; Steels and Tisseli, 2008) augments this information with tags, open-ended keywords entered through mobile phones ( or through web interfaces) as meta-data. The type of data we envision consists of measurements of environmental parameters such as noise or pollutant concentrations combined with tags for geographical location and time. Geographic localisation requires sophisticated technologies such as GPS, GSM-based positioning (Chen et al., 2006; Gonzalez et al., 2008), or localisation through WiFi access points (Rekimoto et al., 2007). On top of this users may tag measurement data with subjective experiences or the suspected source of pollution. For example, a user might indicate that noise at a particular spot on the way home from work is likely to originate from a building site. While there is no restriction in principle, users tend to converge on the same tags when they can see tags of others and their aggregation in tag clouds (Cattuto et al., 2007). Individual participatory sensing data will obviously not have the same quality and accuracy as that obtained from high-end environmental monitoring stations. However, we expect that this issue can be alleviated by collecting massively more data and by using techniques to calibrate and correlate those data. A schematic representation of the underlying ICT architecture is given in Figure 1, with mobile device-based data gathering components on the left-hand side and the server-based community memory implementation on the right-hand side. Mobile application software provides an interface for the user, also allowing tag- 
ging, either automatically (for spatio-temporal data) or manually. It also takes care of data transmission to a central server, which hosts the actual community memory. At the server side more software takes care of aggregating gathered data and visualising it on geographical maps or as tag clouds, as well as providing an interface for users to interact with one another so as to build up their community.

The community memory we propose serves both as an instrument for supporting actions towards policy makers as well as a platform for making the average citizen aware of his urban environmental conditions. That community memories have real value both for the community itself as well as for policy makers is proved by their success in situations going from semi-nomadic Mbendjele Pygmies struggling for the preservation of the rainforests of Congo (Hopkin, 2007) to handicapped people striving for easyto-navigate streets in Barcelona (Steels and Tisselli, 2008). Moreover the community memory acts as a repository of environmental data at a much higher granularity than that of current measuring methods, which moreover includes person-centric information, entirely lacking in present-day surveys (Brussels Instituut voor Milieubeheer, 2002). Therefore community memories resolve both the granularity as well as the awareness issues highlighted in the above. We note that to scale up the centralised setup proposed here one can rely on conventional server duplication and load-balancing techniques.

To experiment with and evaluate the approach described here we are involved in NoiseTube initiative (Maisonneuve et al., 2009). The goal of this ongoing research project is to develop a participatory solution to the monitoring and mapping of urban noise pollution. Concretely a software platform is provided that enables citizens to measure their personal exposure to noise by using GPS-equipped mobile phones as noise sensors. The system allows participants to share geo-localised measurement data though a community memory website in order to contribute to collective monitoring initiatives. These initial experiments demonstrate convincingly the need and the willingness of citizens to be involved, but so far they have been limited in time and space, mostly due to time and financial constraints.

The creation of community memories is now technically feasible largely due to the fact that networked electronic components are becoming more and more wide-spread, versatile and affordable. Nevertheless they require many state-of-the art technologies and even act as a driver for additional advances in several areas of computer science and engineering, such as participatory sensing. Besides the NoiseTube project other preliminary experiments in active participatory sensing of the environment have been conducted, partly organised by governmental organisations and partly by citizen organisations (Ellul, 2008; Mun et al., 2009). The idea of using commodity devices such as mobile phones for scientific purposes and environmental monitoring in particular is also gaining traction outside academia, as illustrated by coverage in science and technology press and mainstream media (Patel-Predd, 2009; The Economist, 2009).

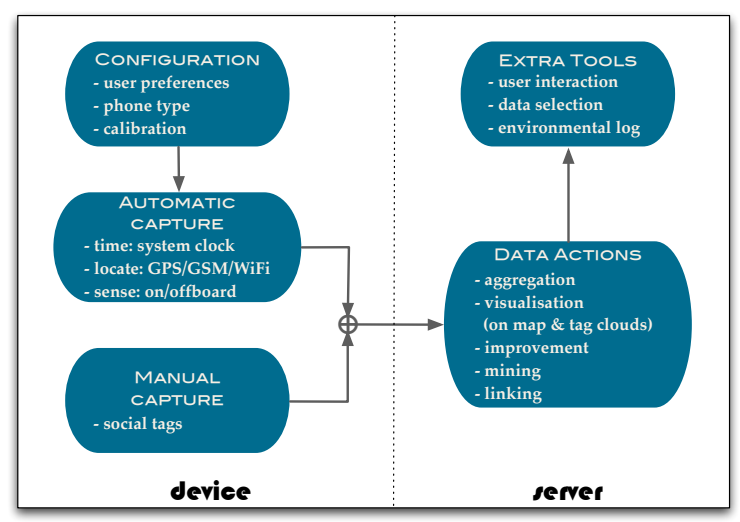

Figure 1: Community memory architecture.

\section{CONCLUSIONS \& FUTURE WORK}

In this paper we present the current status of our work on developing participatory approaches to environmental monitoring. We describe the limitations of current techniques, the advantages of the participatory approach and the technical challenges it brings. NoiseTube, our prototype system, represents a working solution for participative monitoring of urban noise pollution but remains under active development. First, in order to evaluate and further improve the current system, experimental medium-size deployments with volunteering citizens are planned for the near future. Subsequent larger-size experiments are needed to validate the overall participatory approach to environmental monitoring. These efforts require us to tackle several open challenges, such as developing a procedure for estimating the credibility of aggregated data as well as improving the quality of the data through spatio-temporal interpolation or by complementing measurements with propagation methods. Second, we intend to build upon technologies developed and lessons learned to evolve NoiseTube into a more powerful and versatile community memory platform for assessing not only noise but also atmospheric pollution. In this context sensing is more difficult as 
it involves off-board equipment which is also typically less stable. Third, once data sets become large enough one can consider more sophisticated analyses through data mining techniques, or by linking our data repository with databases dealing with topics as diverse as traffic flows, building schedules or disease occurrences. Finally, within the larger context of sustainability we cannot but consider the energy tradeoff of the technological developments we propose. In particular, we need to assess the amount the power our overall solution consumes for different numbers of contributing and consulting users.

\section{ACKNOWLEDGEMENTS}

The first author is supported by the Institute for the encouragement of Scientific Research and Innovation of Brussels (IRSIB/IWOIB) and the second by the Flemish Fund for Scientific Research (FWO).

\section{REFERENCES}

Brussels Instituut voor Milieubeheer (2002). Plan voor structurele verbetering van de luchtkwaliteit en de strijd tegen de opwarming van het klimaat. (in Dutch).

Burke, J. A., , Estrin, D., Hansen, M., Parker, A., Ramanathan, N., Reddy, S., and Srivastava, M. B. (2006). Participatory sensing. In World Sensor Web Workshop (WSWi06) at ACM SenSys i06, October 31, 2006, Boulder, Colorado, USA.

Cattuto, C., Loreto, V., and Pietronero, L. (2007). Semiotic dynamics and collaborative tagging. PNAS, 104(5):1461-1464.

Chen, M. Y., Sohn, T., Chmelev, D., Haehnel, D., Hightower, J., Hughes, J., LaMarca, A., Potter, F., Smith1, I., and Varshavsky, A. (2006). Practical MetropolitanScale Positioning for GSM Phones. In Dourish, P. and Friday, A., editors, Proceedings of UbiComp 2006 (Orange County, CA, USA, September 17-21, 2006), volume 4206/2006 of Lecture Notes in Computer Science, pages 225-242. Springer.

Ellul, C. (2008). Creating Community Maps for the London Thames Gateway. In RGS-IBG Annual International Conference 2008.

European Parliament and Council (2002). Directive 2002/49/EC relating to the Assessment and Management of Environmental Noise. Official Journal of the European Communities, 18.7.2002:12-26.

Gonzalez, M. C., Hidalgo, C. A., and Barabasi, A.-L. (2008). Understanding individual human mobility patterns. Nature, 453(7196):779-782.

Hopkin, M. (2007). Conservation: Mark of respect. Nature, 448:402-403.
Maisonneuve, N., Stevens, M., Niessen, M. E., Hanappe, P., and Steels, L. (2009). Citizen noise pollution monitoring. In dg.o '09: Proceedings of the 10th Annual International Conference on Digital Government Research, pages 96-103. Digital Government Society of North America / ACM Press.

Mun, M., Reddy, S., Shilton, K., Yau, N., Burke, J., Estrin, D., Hansen, M., Howard, E., West, R., and Boda, P. (2009). PEIR, the Personal Environmental Impact Report, as a Platform for Participatory Sensing Systems Research. In MobiSys '09: Proceedings of the 7 th international conference on Mobile systems, applications, and services, pages 55-68. ACM.

Patel-Predd, P. (2009). Cellphones for Science. IEEE Spectrum, 46(2): 16

Rekimoto, J., Miyaki, T., and Ishizawa, T. (2007). LifeTag: WiFi-Based Continuous Location Logging for Life Pattern Analysis. In Hightower, J., Schiele, B., and Strang, T., editors, Location- and Context-Awareness, Third International Symposium, LoCA 2007, Oberpfaffenhofen, Germany, September 20-21, 2007. Proceedings, number 4718 in Lecture Notes in Computer Science, pages 35-49. Springer.

Stapelfeldt, H. and Jellyman, A. (2003). Using GIS in Noise exposure analysis. In Proceedings of the 32nd International Congress and Exposition on Noise Control Engineering (Inter-Noise 2003; Seogwipo, Korea, August 25-28, 2003).

Steels, L. (2006). Semiotic Dynamics for Embodied Agents. IEEE Intelligent Systems, 21(3):32-38.

Steels, L. (2008). Community Memories for Sustainable Societies. Technical report, Sony Computer Science Lab - Paris. To be published on the occasion of the 20th Anniversary of Sony CSL, Tokyo spring 2008.

Steels, L. and Tisseli, E. (2008). Social Tagging in Community Memories. In Social Information Processing Papers from the 2008 AAAI Spring Symposium (March 26-28, 2008, Stanford University), number Technical Report SS-08-06, pages 98-103. The AAAI Press, Menlo Park, California, USA.

Steels, L. and Tisselli, E. (2008). Interfaces for Community Memories. In IUI 2008 Proceedings - 2008 International Conference on Intelligent User Interfaces (January 13-16, 2008, Canary Islands, Spain).

The Economist (2009). Sensors and sensitivity. The Economist - Technology Quarterly, 391(8634):21-22. Technology Quarterly issue.

United Nations Environment Programme (1992). Rio Declaration on Environment and Development. Proclaimed at the UN Conference on Environment and Development (Rio de Janeiro, Brasil, 3-14 June 1992). 
\begin{tabular}{l|l} 
Vrije \\
Universiteit \\
Brussel
\end{tabular}

\section{Abstract}

We propose a particular approach by which computer science can aid on the technological side of sustainable development, which at the same time contributes to raising people's awareness of the issues at hand. In particular we develop a so-called community memory for urban environmental measurement surveys, focusing on noise, microclimate and atmospheric pollution. Our goal is to gather data both in a quantitative way, using participatory mobile sensing, and in a qualitative way, by social tagging. In this way we provide a method for environmental monitoring which is complementary to current modelling approaches.

\section{Motivation}

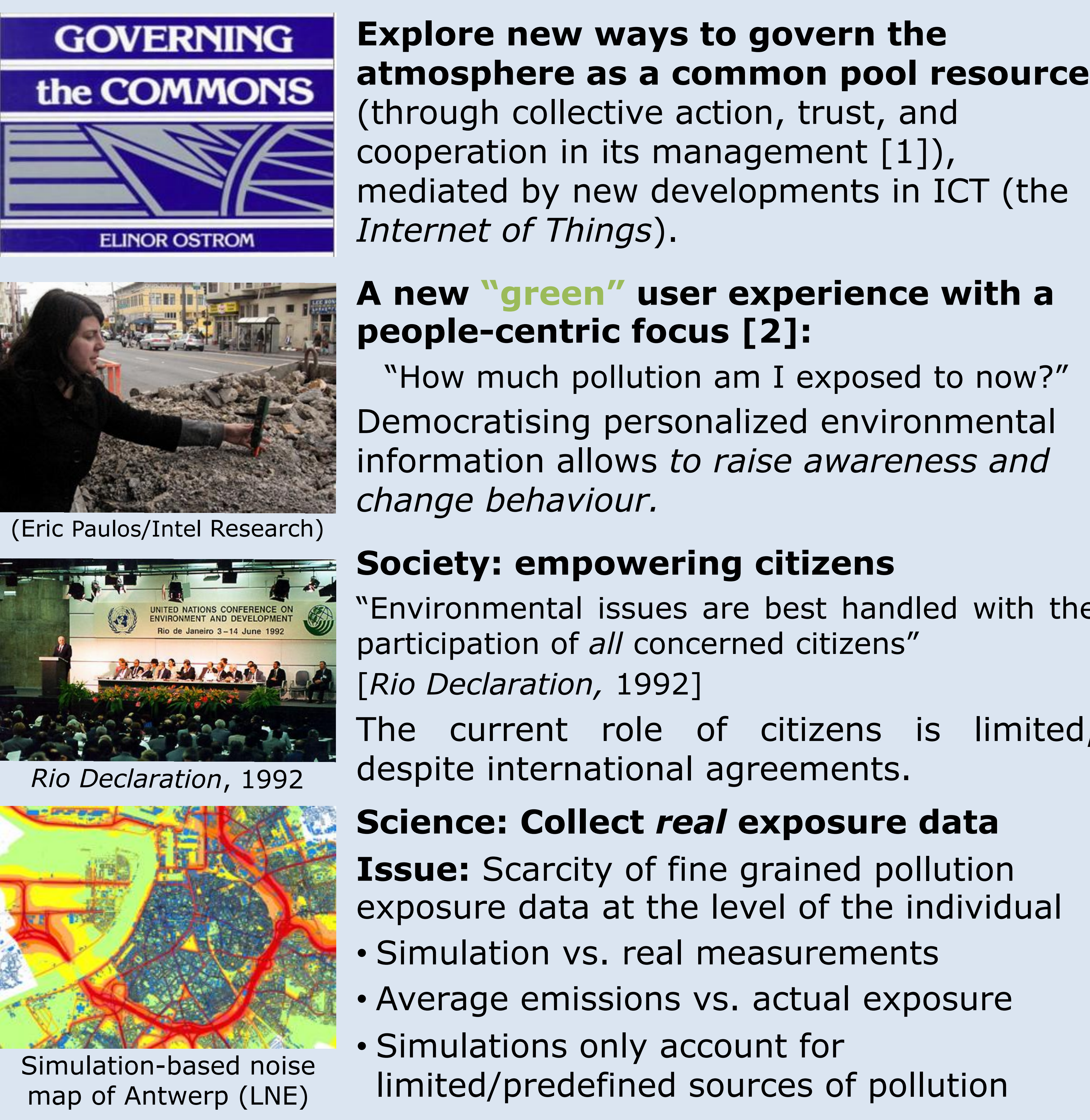

\section{Social tagging[5]}

Issue: Lack of semantic information to facilitate interpretation of sensor data

$\rightarrow$ People as semantic sensors
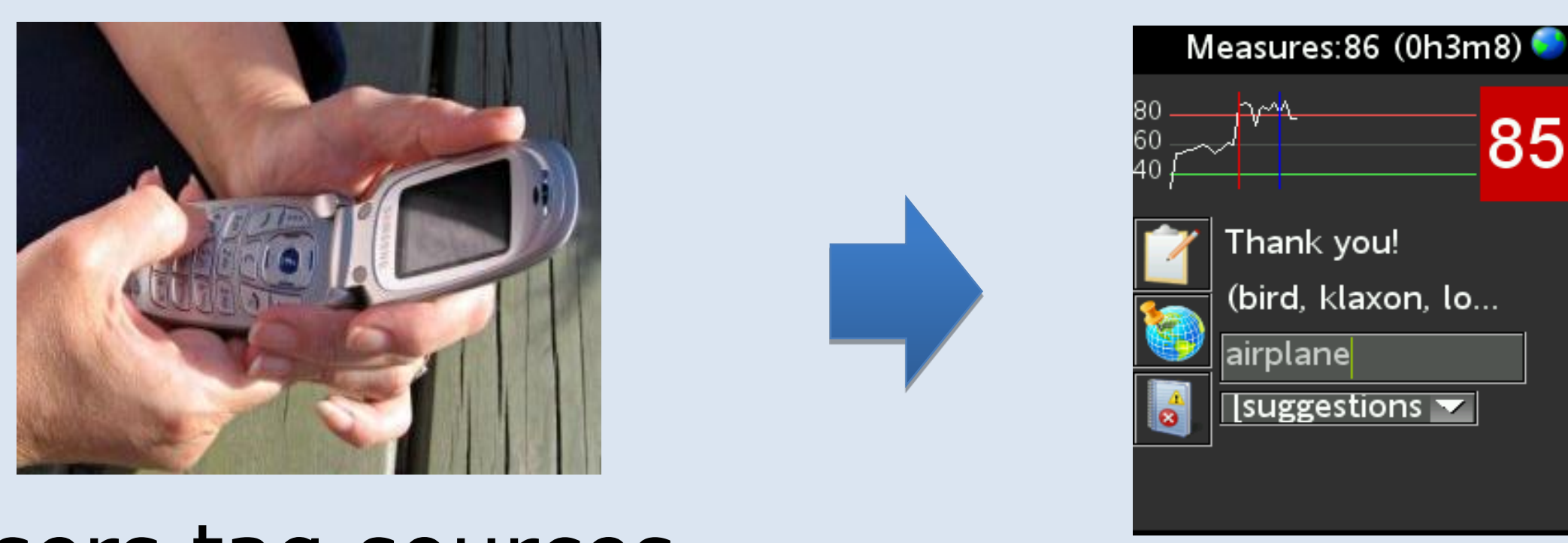

Tags are sent and stored with

Users tag sources of noise, perceived annoyance, etc.

Tags are used to create rich, annotated noise exposure maps

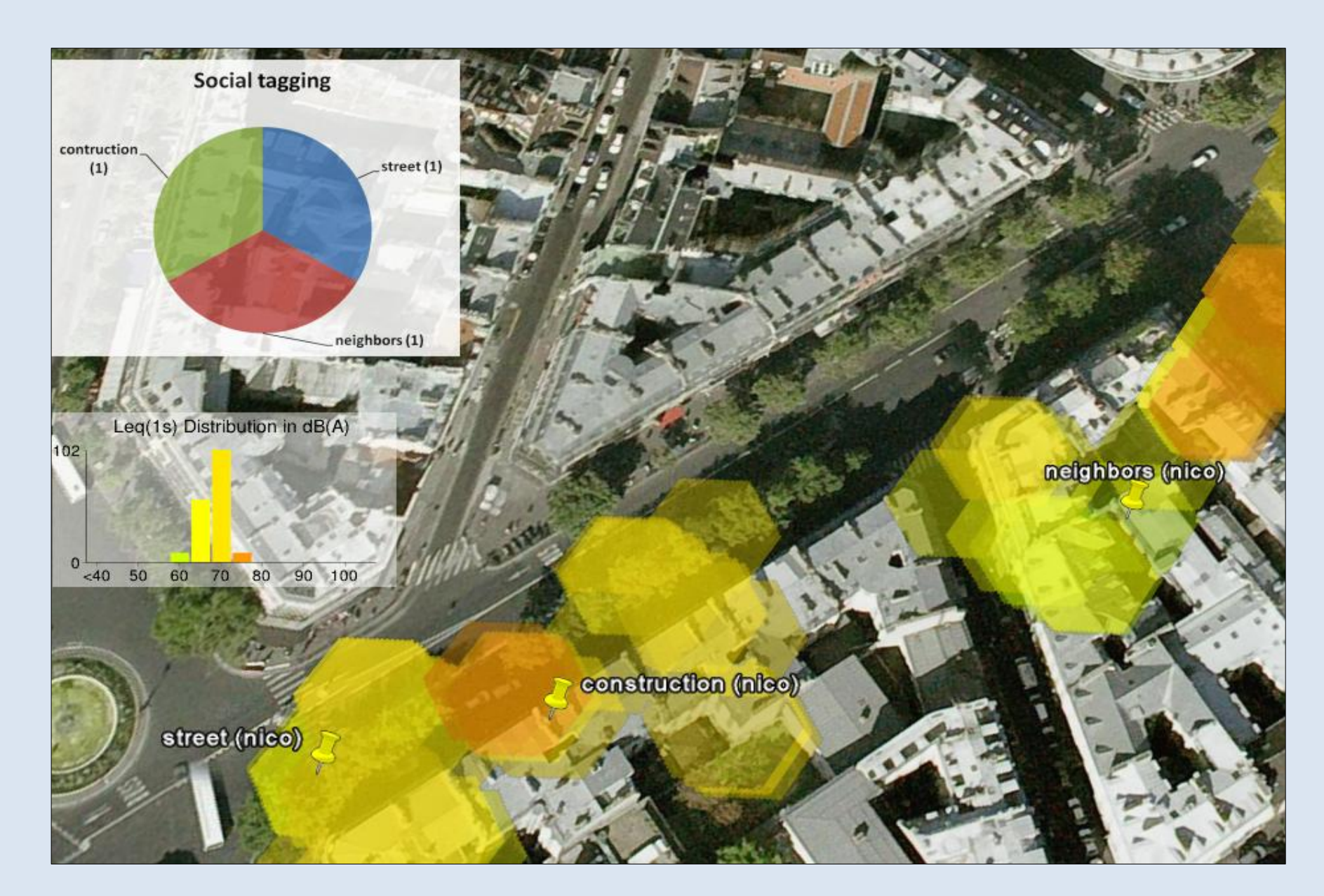

BrusSense Team (www.brussense.be)

\{mstevens, eldhondt\}@vub.ac.be

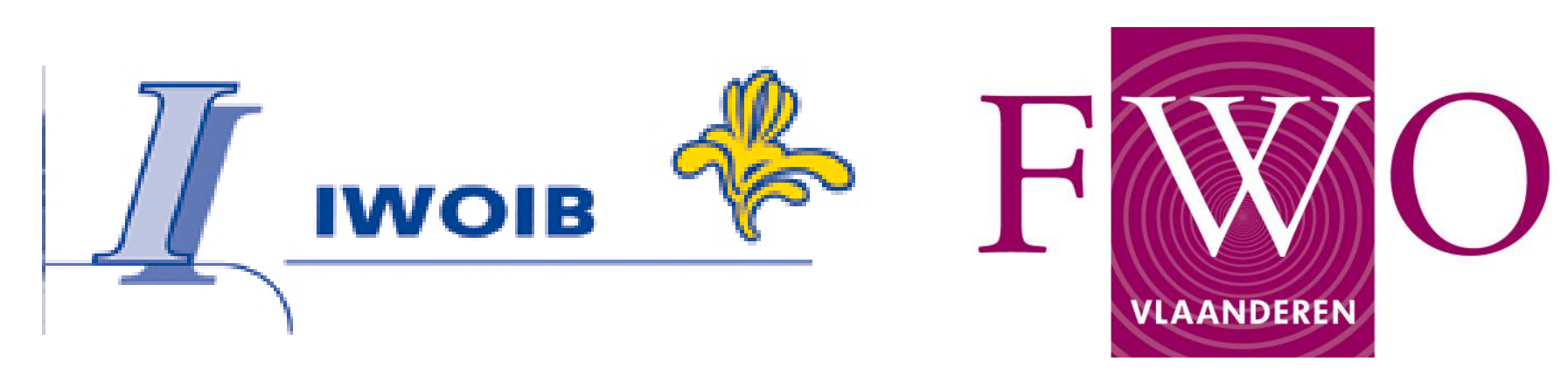

1 Community memories[3]

= collection of ICT tools to collectively manage a common pool of resources

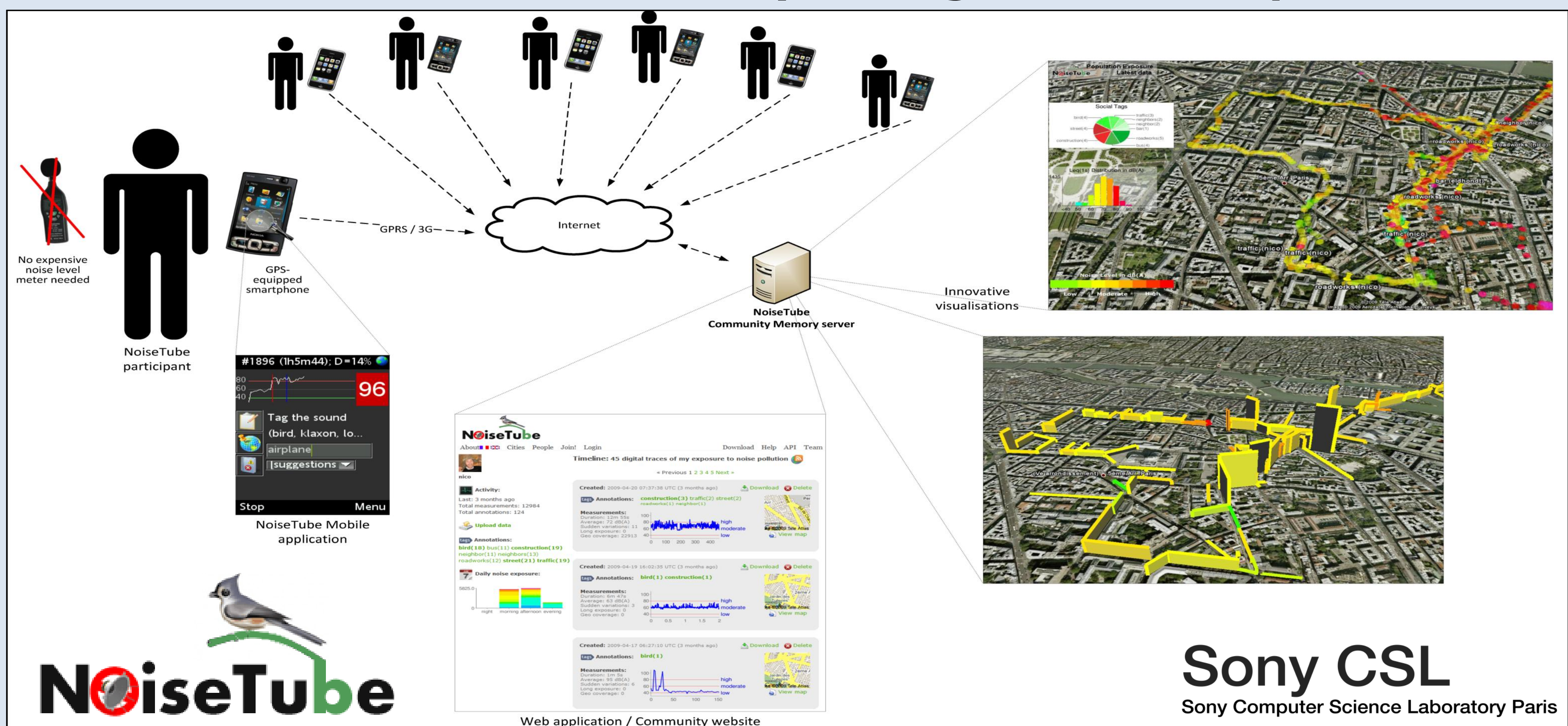

\section{Mobile phone as environmental sensor[4]}

Challenge: Use mobile phones to measure loudness in real-time

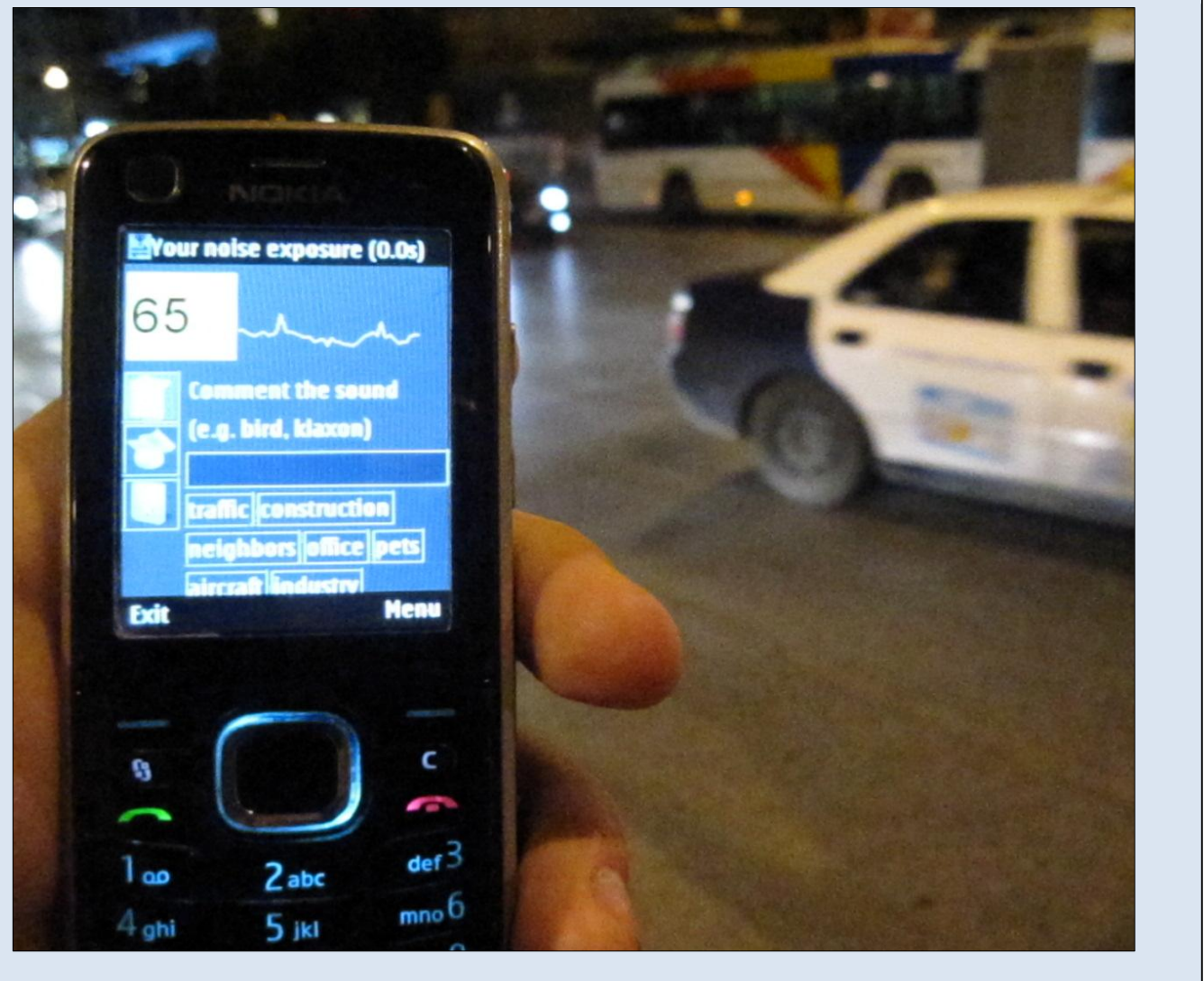

Phone as noise sensor
Signal processing algorithm to compute $L_{e q}(A)$

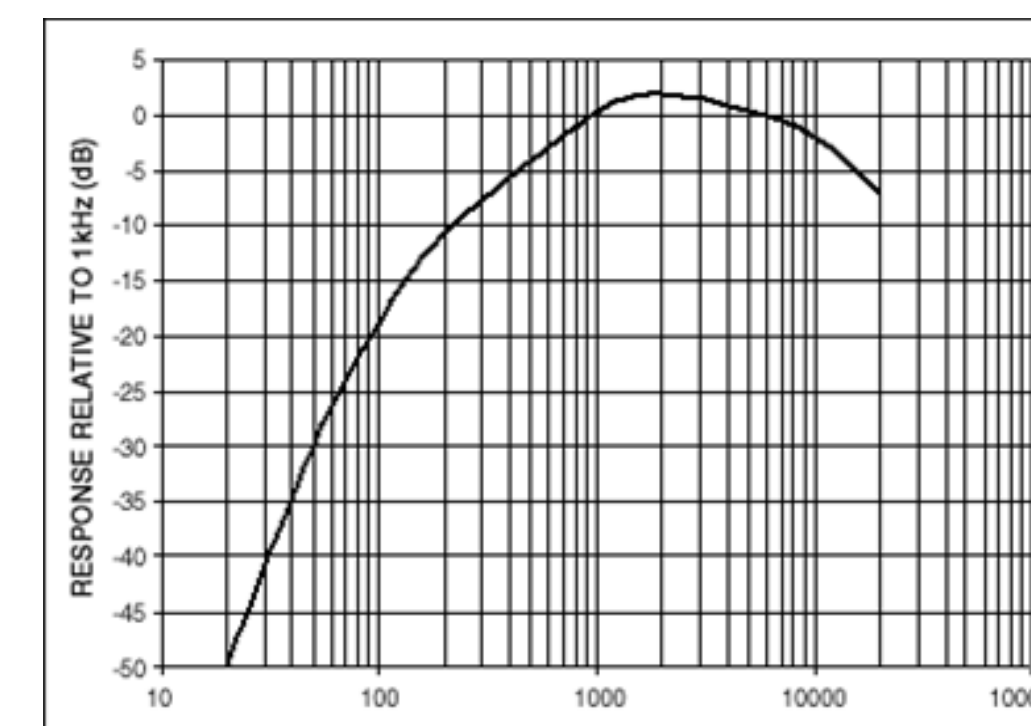

A-weighted filter (models sensitivity of human ear) $+\quad L_{e q}=10 \log \frac{1}{T} \int_{0}^{T} \frac{p^{2}}{p_{0}^{2}} d t$

Computation of equivalent continuous sound level (in $\mathrm{dB}(\mathrm{A})$ )

$+$

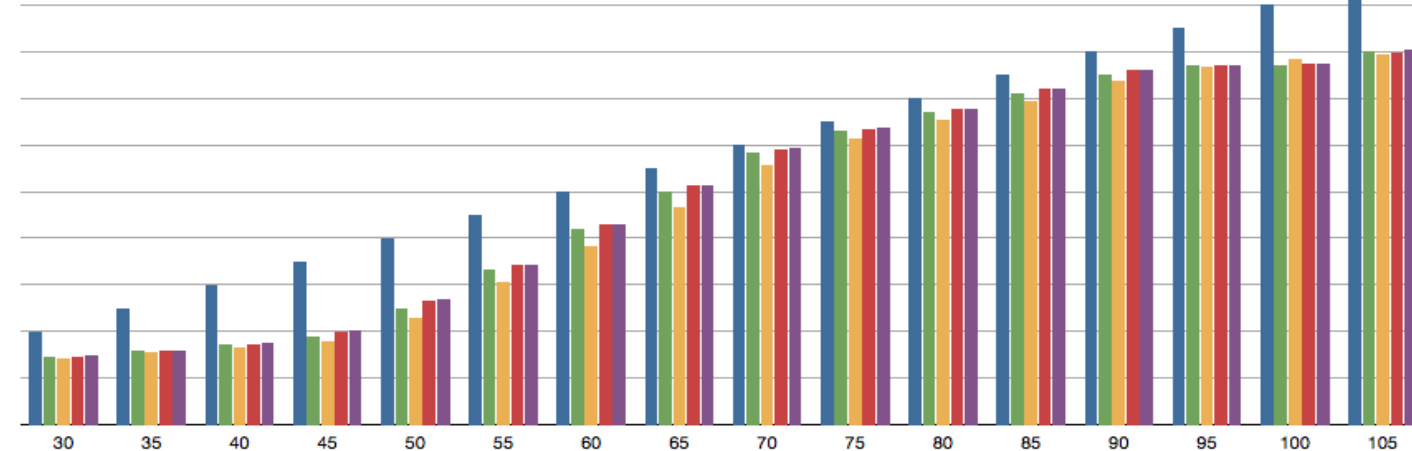

Phone-specific correction function (reference \& 4 Nokia 5230s shown)

Calibration experiments to evaluate \& improve accuracy
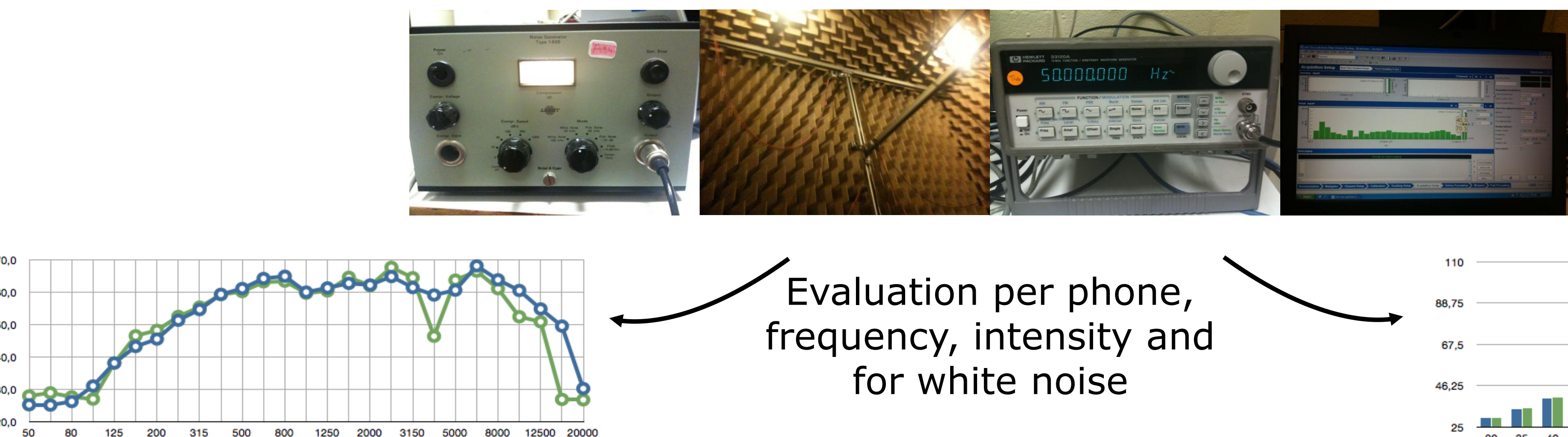

\section{Validation}

Does it work? Imagine a typical scenario: mapping noise pollution in a given area by a limited group of (untrained) citizens.

1) Volunteers from Ademloos, an Antwerp-based action group labouring for more sustainably city life (focus on traffic circulation and green spaces)

2) Limit experiment in space and time: focus on one neighbourhood \& two time slots (peak and off-peak)
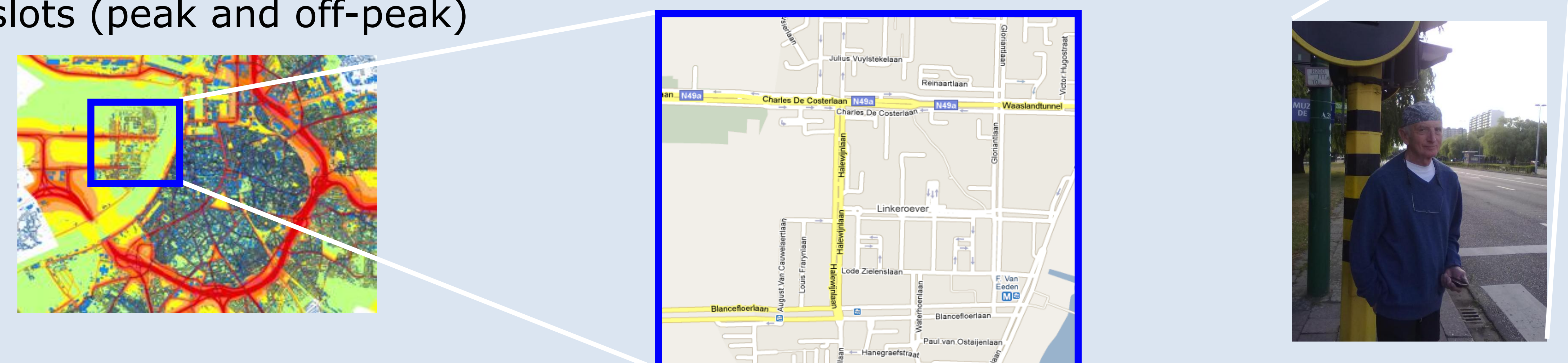

3) Restrict free variables insofar as possible (measurement technique, phone variability, itinerary followed)

Challenges:

- Smart filtering \& correction of faulty data

- Data aggregation: from simple averaging to more advanced interpolation techniques.

- Achieve accuracies as for simulation maps ( $\pm 5 \mathrm{~dB})$

\section{Future work}

- Case study: process measurements, create noise maps, include more participants

- Incorporate context-orientation technology ${ }^{[6]}$

- Investigate combination of simulation \& participatory techniques

Extend approach to air pollution \& microclimate (using external sensors)

$\rightarrow$ BrusSense project (www.brussense.be)

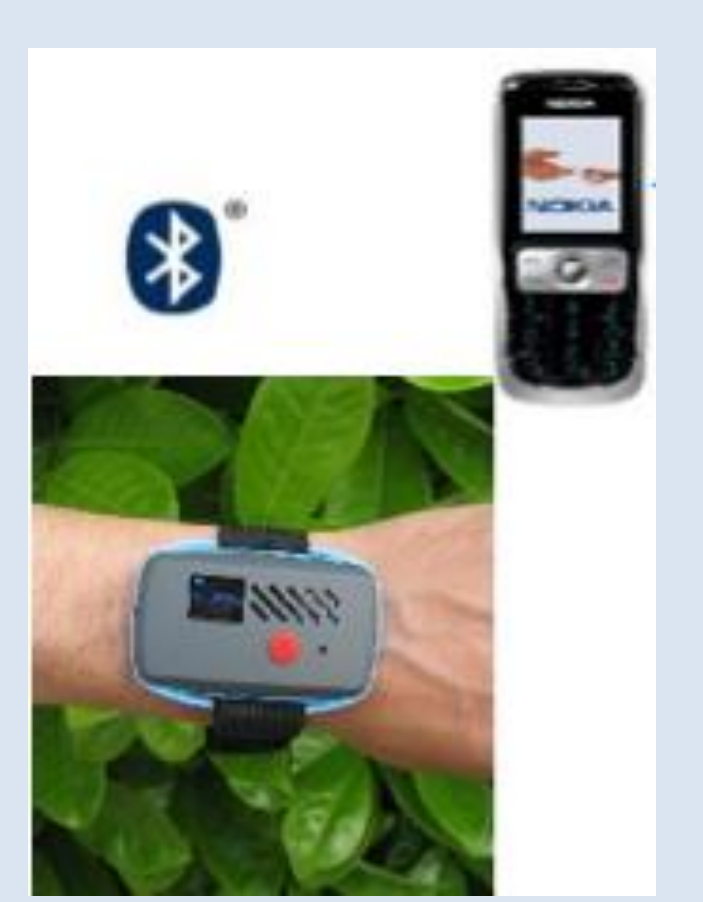

Combination of phone \& "environmental watch" (from www.sensaris.com)

\section{References}

[1] E. Ostrom. Governing the commons: The Evolution of Institutions for Collective Action. Cambridge University Press, 1990.

[2] E. Paulos. Citizen Science: Enabling Participatory Urbanism. Handbook of Research on Urban Informatics, IGI Global, 2009.

[3] L. Steels. Community memories for sustainable societies. Publication for the 20th Anniversary of the

4] N. Maisonneuve, M. Stevens, M. E. Niessen, P. Hanappe \& L. Steels. Citizen Noise Pollution Monitoring. Proceedings of the 10th Annual International Conference on Digital Government Research, 2009. 5] Steels \& Tiselli. Social Tagging in Community Memories. Proceedings of the AAAI Spring Symposium On Social Information Processing, 2008.

[6] J. Vallejos, M. Stevens, E. D'Hondt, N. Maisonneuve et al. Context-aware Resource Sharing for Peoplecentric Sensing. First Int. Workshop on Software Research and Climate Change (WSRCC'09), 2009. 